\title{
Randomized clinical trial of antibiotic and prostaglandin treatments for uterine health and reproductive performance in dairy cows
}

\author{
J. Dubuc, ${ }^{\star 1,2}$ T. F. Duffield, ${ }^{\star}$ K. E. Leslie, ${ }^{\star}$ J. S. Walton, $†$ and S. J. LeBlanc ${ }^{\star}$ \\ *Department of Population Medicine, and \\ †Department of Animal and Poultry Science, University of Guelph, Guelph, Ontario, N1G 2W1, Canada
}

\begin{abstract}
The objectives of this study were to assess the efficacy of antibiotic treatment for preventing postpartum uterine disease among cows at high risk of uterine disease, and to assess the efficacy of $\mathrm{PGF}_{2 \alpha}$ for treating cytological endometritis (CYTO) and purulent vaginal discharge (PVD). A total of 2,178 Holstein cows in 6 herds were enrolled in a randomized clinical trial. Within $24 \mathrm{~h}$ after parturition, cows were classified at being at high risk of uterine disease (HRUD; $\mathrm{n}=1,017$ ) if they had twins, dystocia, or retained placenta. All remaining cows were classified as being at low risk of uterine disease (LRUD; $n=1,161$ ). Cows in the HRUD group were randomly allocated in a factorial design to receive ceftiofur crystalline free acid (CCFA) at $24 \mathrm{~h}$ after parturition or be untreated, and to receive dinoprost $\left(\mathrm{PGF}_{2 \alpha}\right)$ at 35 and $49( \pm 3)$ days in milk (DIM) or to be untreated. Cows in LRUD were randomly allocated to receive $\mathrm{PGF}_{2 \alpha}$ at 35 and $49( \pm 3)$ DIM or to be untreated. Serum progesterone was measured at $21,35,49$, and $63( \pm 3)$ DIM. Cows were examined at $35( \pm 3$; exam 1$)$ and $56( \pm 3$; exam 2$)$ DIM for CYTO (by cytobrush device; $\geq 6 \%$ polymorphonuclear cells in endometrial cytology) and for PVD (by Metricheck device; mucopurulent or purulent vaginal discharge). Statistical analyses were performed using multivariable logistic regression models accounting for herd clustering. Treatment with CCFA in HRUD cows was not associated with the probability of metritis overall, but interactions occurred such that CCFA decreased the incidence of metritis among HRUD cows that did not have retained placenta and among cows of parity $\geq 2$. Treatment with CCFA in HRUD cows decreased the probability of PVD at exam 1. Treatment with $\mathrm{PGF}_{2 \alpha}$ did not affect the probability of cure of CYTO or PVD irrespective of progesterone concentration at the time
\end{abstract}

Received August 25, 2010.

Accepted November 30, 2010.

${ }^{1}$ Corresponding author: jocelyn.dubuc@umontreal.ca

${ }^{2}$ Current address: Faculté de médecine vétérinaire, Université de Montréal, C.P. 5000, Saint-Hyacinthe, Québec, J2S 7C6, Canada. of treatment. Among cows affected by CYTO or PVD at exam 1, 66 and $63 \%$, respectively, had spontaneously cured at exam 2. Cows persistently affected at exam 2 had an increased time to pregnancy and were more likely to have both CYTO and PVD at exam 1. Administration of $\mathrm{PGF}_{2 \alpha}$ at both 5 and 7 wk postpartum did not mitigate the effects of CYTO or PVD on reproductive performance. Clinical approaches to treatment of chronic postpartum reproductive tract infection and inflammation should be reassessed.

Key words: metritis, endometritis, prostaglandin, ceftiofur

\section{INTRODUCTION}

The postpartum uterine diseases metritis and endometritis are common in dairy cows (LeBlanc et al., 2002a; Gilbert et al., 2005; Overton and Fetrow, 2008). Metritis is a condition causing systemic signs of illness (fever, anorexia, decreased milk production) characterized by a foul-smelling, brown-red, watery vaginal discharge occurring within the first 21 DIM (Sheldon et al., 2006). Endometritis is based on examination $>21$ DIM using diagnostic criteria associated with detrimental effects on subsequent reproductive performance (LeBlanc et al., 2002a). Endometritis is diagnosed cytologically as endometrial inflammation, or clinically as mucopurulent or purulent vaginal discharge (LeBlanc et al., 2002a; Kasimanickam et al., 2004; Gilbert et al., 2005). Cytological endometritis (CYTO) and purulent vaginal discharge (PVD) were shown to be distinct manifestations of reproductive tract disease, with their own sets of risk factors (Dubuc et al., 2010b). It was proposed that the term PVD be used instead of clinical endometritis, because PVD was not necessarily indicative of endometrial inflammation (Dubuc et al., 2010a).

During pregnancy, the uterine lumen is sterile (Földi et al., 2006). At parturition, the cervix opens and allows bacterial contamination from the vagina and the environment into the uterus (Elliott et al., 1968; Griffin et al., 1974a; Földi et al., 2006). This contamination affects over $90 \%$ of cows (Elliott et al., 1968; Griffin 
et al., 1974a; Sheldon et al., 2002b). Many species of bacteria can be found in the uterus in the early postpartum period (Elliott et al., 1968; Griffin et al., 1974a; Sheldon et al., 2002b). In the first $10 \mathrm{~d}$ after calving, bacteria such as Streptococcus spp. and Staphylococcus spp. are frequently isolated in animals without signs of metritis, whereas Escherichia coli, Arcanobacterium pyogenes, Fusobacterium necrophorum, and Prevotella melaninogenicus are commonly isolated from animals with metritis (Elliott et al., 1968; Sheldon et al., 2002a; Williams et al., 2005). The presence of E. coli in the uterus during the first week postpartum can affect the function of polymorphonuclear (PMN) cells (neutrophils) and leads to PVD (Dohmen et al., 2000; Zerbe et al., 2001). Infection with E. coli in the first week postpartum is associated with infection with $A$. pyogenes in wk 3, and in turn with the prevalence of CYTO and impaired reproductive performance (Santos et al., 2008). Risk factors such as retained placenta (RP), twins, and dystocia can increase uterine contamination early postpartum (Gröhn et al., 1990; Noakes et al., 1991; Risco and Hernandez, 2003) and lead to a higher risk of uterine diseases (Dubuc et al., 2010b).

Parenteral administration of ceftiofur sodium (Drillich et al., 2001) or ceftiofur hydrochloride (Chenault et al., 2004) has been shown to be effective for treatment of metritis. Ceftiofur reduced the incidence of metritis in cows with retained fetal membranes (Drillich et al., 2003, 2006b; Risco and Hernandez, 2003). This effect was proposed to be linked with a decrease in uterine pathogen load in the early postpartum period (Risco and Hernandez, 2003). Ceftiofur crystalline free acid (CCFA) is a long-acting antibiotic for treatment of respiratory disease and footrot in cattle (Hibbard et al., 2002a,b; Van Donkersgoed et al., 2008). However, little is known regarding its efficacy for preventing metritis, CYTO, or PVD. Administered early in the postpartum period, CCFA could decrease uterine pathogen load and so reduce the incidence of subsequent uterine disease (McLaughlin et al., 2010; Stanisiewski et al., 2010).

A large body of conflicting data exists regarding the benefit of $\mathrm{PGF}_{2 \alpha}$ administration for improving uterine health and reproductive performance (Burton and Lean, 1995; LeBlanc, 2008; Galvão et al., 2009). The proposed benefits of $\mathrm{PGF}_{2 \alpha}$ would be from induction of estrus in cows having a responsive corpus luteum, causing evacuation of uterine contaminants (Kasimanickam et al., 2005b), or by improvement of uterine defenses by temporarily increasing estrogen and decreasing progesterone concentrations in plasma (Kasimanickam et al., 2005b).

Uterine contamination decreases over time (Elliott et al., 1968; Griffin et al., 1974a; Sheldon et al., 2002a) and diagnostic criteria for uterine diseases vary during the postpartum period (LeBlanc et al., 2002a; Gilbert et al., 2005; Galvão et al., 2009). However, limited information exists on the proportions of cows that spontaneously recover from CYTO and PVD or on the risk factors associated with persistent uterine infection and inflammation during the postpartum period (Gautam et al., 2010).

The first objective of this study was to determine whether antimicrobial therapy against putative uterine pathogens, targeted at cows with known risk factors for metritis, could reduce the incidence of metritis, PVD, and CYTO. The hypothesis was that selective antibiotic therapy soon after parturition would reduce the challenge from uterine bacterial pathogens (E. coli and anaerobes) and thereby reduce the incidence of uterine diseases. Ceftiofur was chosen because data were available (Drillich et al., 2006a) that support it being able to achieve therapeutic concentrations in the uterus and thereby test the hypothesis. The second objective was to determine the effect of $\mathrm{PGF}_{2 \alpha}$ treatment for improving uterine health and reproductive performance. The hypothesis was that $\mathrm{PGF}_{2 \alpha}$ would improve the probability of cure of CYTO and PVD, and would improve pregnancy rate. The third objective was to determine the proportions of cows that spontaneously recover from CYTO or PVD.

\section{MATERIALS AND METHODS}

A total of 2,178 Holstein cows from 6 commercial herds (3 in southwestern Ontario, Canada, and 3 in western New York State) were enrolled in a randomized clinical trial. Cows were housed in freestall barns, and herd size ranged from 300 to 1,000 cows. The study was conducted from September 2007 to November 2008. Participating herds were recruited based on convenience, but were required to use monthly DHIA milk recording service. Cows were enrolled only once during the study.

In 3 herds, all cows were enrolled in the study. At parturition, cows experiencing dystocia (pull necessitating $\geq 2$ people or a calf-jack; assistance for longer than $15 \mathrm{~min}$; veterinary-assisted), delivering twins, or having RP ( $\geq 24 \mathrm{~h}$ after parturition) were enrolled in the high risk of uterine disease group (HRUD; $\mathrm{n}=$ 490). All remaining cows in these 3 herds that were unaffected by the preceding conditions were enrolled in the low risk of uterine disease group (LRUD; $\mathrm{n}=$ 1,161). In 3 other herds, only cows classified as HRUD were enrolled in the study $(\mathrm{n}=527)$. Enrolling all cows (HRUD and LRUD) in 3 herds and only HRUD cows in 3 other herds enabled us to obtain sufficient sample sizes for each group (HRUD and LRUD). 


\section{HRUD Group}

Within $24 \mathrm{~h}$ after parturition, cows were randomly assigned within herd and in balanced blocks of 4 to receive a single treatment of CCFA (Excede, Pfizer Animal Health, Kirkland, Québec, Canada) at a dose of $6.6 \mathrm{mg} / \mathrm{kg}$ subcutaneously at the base of the ear, or to be untreated controls (no placebo was used). To detect a main effect of CCFA reducing the incidence of metritis or PVD from 30 to $20 \%$, allowing for 3 covariates, with $95 \%$ confidence and $80 \%$ power, required 380 cows per group (Dohoo et al., 2003). Cows were also randomly assigned, within the CCFA allocation block, to receive $25 \mathrm{mg}$ of dinoprost intramuscularly $\left(\mathrm{PGF}_{2 \alpha}\right.$; Lutalyse, Pfizer Animal Health) twice, at $35( \pm 3)$ and 49 ( \pm 3 ) DIM, or to receive no $\mathrm{PGF}_{2 \alpha}$ (no placebo was used). Therefore, cows were randomly allocated in this factorial design clinical trial to 1 of 4 treatment groups: negative controls, CCFA treatment only, $\mathrm{PGF}_{2 \alpha}$ treatment only, or both CCFA and $\mathrm{PGF}_{2 \alpha}$ treatments. Individuals involved in the diagnosis of uterine diseases were blinded to treatment allocation.

\section{LRUD Group}

Within $24 \mathrm{~h}$ after parturition, cows were randomly assigned to receive $25 \mathrm{mg}$ of dinoprost intramuscularly $\left(\mathrm{PGF}_{2 \alpha}\right.$; Lutalyse, Pfizer Animal Health) twice, at 35 $( \pm 3)$ and $49( \pm 3)$ DIM, or to be untreated controls (no placebo was used). No cows in the LRUD group received CCFA. To measure a treatment $\left(\mathrm{PGF}_{2 \alpha}\right)$ effect that would improve first-service conception risk from 30 to $40 \%$, allowing for 3 covariates with low correlation with treatment, with $95 \%$ confidence and $80 \%$ power, required approximately 470 cows per treatment group (Dohoo et al., 2003). Individuals involved in the diagnosis of uterine diseases were blinded to treatment allocation.

\section{Sample and Data Collection}

Although experimental treatment allocation was different between the LRUD and HRUD groups, sample and data collection were the same. Farms were visited weekly by a technician and a veterinarian. Body condition score was measured at enrollment in the study and at $63( \pm 3)$ DIM (Ferguson et al., 1994). A blood sample from the coccygeal blood vessels was collected into an evacuated sterile tube without anticoagulant (Vacutainer, Becton Dickinson, Franklin Lakes, NJ) from each cow at 21, 35, 49, and $63( \pm 3)$ DIM. Samples were kept chilled and allowed to clot. Within $5 \mathrm{~h}$ of blood collection, samples were centrifuged to harvest serum, which was frozen at $-20^{\circ} \mathrm{C}$. Serum progesterone $(\mathbf{P} 4)$ analysis was conducted at the Animal Health Laboratory of the University of Guelph with a sequential competitive ELISA (Immulite, Siemens, Mississauga, Ontario, Canada) validated for use in cattle (Martin et al., 2007). The inter- and intraassay CV for P4 were 9.6 and $7.2 \%$, respectively.

Cows were examined for vaginal discharge, cervical diameter, and endometrial inflammation at $35( \pm 3$; exam 1) and $56( \pm 3$; exam 2) DIM. Endometrial cytology samples were collected in the dorsal aspect of the uterine body using the cytobrush technique (Kasimanickam et al., 2005a) and were smeared on glass microscope slides. Slides were stained with modified Wright-Giemsa stain (Protocol Hema-3; Biochemical Sciences, Swedesboro, NJ) and were examined under a microscope to count the number of PMN within 100 cells (\% PMN). The clinical examination of cows was performed using the Metricheck device (Simcro, Waikato, New Zealand) and scoring scale (McDougall et al., 2007) and by measuring cervical diameter by transrectal palpation.

Individual cow data were recorded on farm using DairyComp 305 (Valley Agricultural Software, Tulare, CA). Individual cow parity group (first; second or greater) and season of calving (winter: December to February; spring: March to May; summer: June to August; fall: September to November) were recorded. Metritis was diagnosed by herd managers using a standardized definition: the presence of a foul-smelling, red-brown, watery vaginal discharge with rectal temperature $>39.5^{\circ} \mathrm{C}$ and systemic signs of illness (dullness, decreased appetite, decreased milk production) $<21$ DIM (Sheldon et al., 2006). Cows diagnosed with metritis were treated according to farm protocol, typically with ceftiofur hydrochloride or procaine penicillin, according to product manufacturer's label.

All herds used AI exclusively after a voluntary waiting period of $63 \mathrm{~d}$. All herds relied on estrus detection for their first breeding at the end of the voluntary waiting period. If cows were not first bred by 70 to 80 DIM, and for subsequent breedings after diagnosis of nonpregnancy, cows were enrolled on an ovulation synchronization program. The objective of the experimental treatments with $\mathrm{PGF}_{2 \alpha}$ was to measure their effects on reproductive health, separate from effects on synchronization of estrus for breeding management. Therefore, enrollment on an ovulation synchronization program could only occur $>21 \mathrm{~d}$ after the final administration of $\mathrm{PGF}_{2 \alpha}$. Reproductive data were collected until 300 DIM or until culling if earlier. Pregnancy diagnosis was performed by transrectal palpation between 35 and $49 \mathrm{~d}$ after the last insemination. 


\section{Statistical Analyses}

Individual cow data were exported from DairyComp 305 to Microsoft Excel (Microsoft Corp., Richmond, WA). Statistical analyses were performed with SAS (version 9.2, SAS Institute Inc., Cary, NC), considering the cow as the unit of interest.

Body condition scores at parturition and $63 \mathrm{~d}$ after were classified as fat $(\geq 3.75)$, moderate (3.0 to 3.5$)$, or thin $(\leq 2.75)$. Progesterone data were dichotomized, using a threshold of $1 \mathrm{ng} / \mathrm{mL}$ to indicate the presence of an active corpus luteum. Diagnostic criteria for uterine diseases (CYTO and PVD) were established based on detrimental effects on subsequent reproductive performance, using a subsample of the cows enrolled in the current study that were not treated with $\mathrm{PGF}_{2 \alpha}$ (Dubuc et al., 2010a). Thus, CYTO was defined as the presence of $\geq 6 \% \mathrm{PMN}$ and $\geq 4 \% \mathrm{PMN}$ in endometrial cytology at exam 1 and exam 2, respectively. Diagnostic criteria for PVD were defined as the presence of mucopurulent or purulent vaginal discharge at exam 1 and exam 2. Cervical diameter was not associated with a detrimental effect on reproduction. Cytological endometritis and PVD had additive detrimental effects on reproductive performance. Uterine health status was classified as CYTO only, PVD only, both CYTO and PVD, or unaffected.

HRUD Group. The effect of CCFA on the probability of metritis was evaluated in 2 steps. First, a logistic regression model (GLIMMIX procedure) containing only CCFA as a predictor and herd as a random effect was used. Then, a multivariable logistic regression model (GLIMMIX procedure), considering herd as a random effect, was built using a backward elimination procedure until only significant variables or interactions were retained $(P<0.05)$. Predictors offered to this model were CCFA treatment, parity group, dystocia, twins, RP, season, BCS at parturition, and interactions with the main effect of CCFA treatment. Least squares means of adjusted disease prevalence were obtained for variables retained in the final model.

Uterine health classifications (CYTO only, PVD only, or both) at exam 1 were used as outcomes in multivariable logistic regression models, with herd as a random effect (GLIMMIX procedure). Experimental treatment (CCFA) was forced into all models. Predictors offered to the models were parity group, dystocia, RP, twins, BCS at parturition, metritis, $\mathrm{P} 4>1 \mathrm{ng} / \mathrm{mL}$ at 21 or 35 DIM or both, season, first test-day milk production data, DIM at first test-day, and interactions with CCFA treatment. A manual backward elimination procedure was used until only significant variables or interactions were retained $(P<0.05)$.
Similarly, uterine health classifications (CYTO only, PVD only, or both) at exam 2 were used as outcomes in multivariable logistic regression models, with herd as a random effect (GLIMMIX procedure). Experimental treatments (CCFA and $\mathrm{PGF}_{2 \alpha}$ ) were forced into all models. Predictors offered to the models included those offered for the exam 1 models, the interaction of CCFA and $\mathrm{PGF}_{2 \alpha}, \mathrm{P} 4>1 \mathrm{ng} / \mathrm{mL}$ at $49 \mathrm{DIM}$, and uterine health status at exam 1 .

LRUD Group. A similar approach to the HRUD group was used, except that no models were built for metritis or for uterine health status at exam 1, because CCFA was not used as an experimental treatment. Model building for uterine health status at exam 2 (CYTO only, PVD only, or both) was performed as for the HRUD group. Experimental $\mathrm{PGF}_{2 \alpha}$ treatment was forced into all models. Predictors offered to the models were parity, BCS at parturition, metritis, season, P4 $>1 \mathrm{ng} / \mathrm{mL}$ at 21,35 , or 49 DIM, first test-day milk production data, DIM at first test-day, uterine health status at exam 1, and interactions with the main effect of $\mathrm{PGF}_{2 \alpha}$ treatment. A manual backward elimination procedure was used to build the final model until only significant variables or interactions were retained $(P<$ 0.05).

Both HRUD and LRUD Groups. First-service pregnancy risk (FSPR; probability of pregnancy at first service) was considered as one outcome measure of reproductive performance in a multivariable logistic regression model (GLIMMIX procedure) with herd as a random effect. Predictors offered to the model included parity group, dystocia, retained placenta, twins, BCS at parturition, metritis, season, $\mathrm{P} 4>1 \mathrm{ng} / \mathrm{mL}$ at 21 , 35, 49, or 63 DIM, first test-day milk production data, DIM at first test-day, as well as $\mathrm{PGF}_{2 \alpha}$ experimental treatment (forced into the model), its interactions with other predictors, and the risk group for uterine disease (HRUD or LRUD). A backward elimination procedure was used until only significant variables, or their interactions, were retained $(P<0.05)$. A Cox proportional hazard model (PHREG procedure) of time to first service, up to 100 DIM, was used to evaluate the effect of $\mathrm{PGF}_{2 \alpha}$ treatment on interval to first service. Herds were treated as strata to account for clustering (Gröhn et al., 1998). The assumption of proportionality of hazards in the model was assessed graphically by plotting the logarithm of the hazard function by the logarithm of the time. If predictors did not have proportional hazards over time, an interaction term of the log time at risk and the predictor was forced into the model (Dohoo et al., 2003). A similar Cox proportional hazard model (PHREG procedure) was used for evaluating the effect of CCFA treatment (HRUD only), $\mathrm{PGF}_{2 \alpha}$ treat- 
Table 2. Prevalence of uterine diseases at $35( \pm 3$; exam 1$)$ and 56 ( \pm 3 ; exam 2) DIM in 2,072 Holstein cows enrolled in a clinical trial investigating the effect of ceftiofur crystalline free acid and $\mathrm{PGF}_{2 \alpha}$ on uterine health

\begin{tabular}{lccc}
\hline & \multicolumn{3}{c}{ Classification of risk for uterine disease $^{2}$} \\
\cline { 2 - 4 } Item $^{1}$ & LRUD & HRUD & Overall \\
\hline Exam 1 & $(\mathrm{n}=1,116)$ & $(\mathrm{n}=956)$ & $(\mathrm{n}=2,072)$ \\
CYTO only (\%) & 13.3 & 13.1 & 13.2 \\
PVD only (\%) & 4.9 & 14.7 & 9.4 \\
Both (\%) & 3.6 & 10.4 & 6.7 \\
Exam 2 & $(\mathrm{n}=1,095)$ & $(\mathrm{n}=927)$ & $(\mathrm{n}=2,022)$ \\
CYTO only (\%) & 9.5 & 10.0 & 9.8 \\
PVD only (\%) & 4.2 & 10.8 & 7.2 \\
Both (\%) & 2.6 & 5.7 & 4.0 \\
\hline
\end{tabular}

${ }^{1} \mathrm{CYTO}=$ cows diagnosed with cytological endometritis only; PVD $=$ cows diagnosed with purulent vaginal discharge only; Both $=$ cows diagnosed with both cytological endometritis and purulent vaginal discharge.

${ }^{2}$ LRUD $=$ low risk of uterine disease group (cows without retained placenta, twins, or dystocia); HRUD = high risk of uterine disease group (cows with retained placenta, twins, or dystocia).

or $\mathrm{PGF}_{2 \alpha}$ had no effect $(P>0.10)$ on the prevalence of CYTO only, PVD only, or both at exam 2, accounting for uterine health status at exam 1 . No interaction $(P$ $>0.20$ ) between the effects of CCFA and $\mathrm{PGF}_{2 \alpha}$ was observed in these models. Serum P4 $>1 \mathrm{ng} / \mathrm{mL}$ at 35 or 49 DIM ( 53 and $70 \%$ of HRUD cows, respectively) and its interaction with $\mathrm{PGF}_{2 \alpha}$ administration at these times were not significant $(P>0.20)$ in these models.

\section{LRUD Group}

A total of 1,161 cows from 3 herds were enrolled in the LRUD group. Treatment with $\mathrm{PGF}_{2 \alpha}$ had no effect on the prevalence of CYTO only, PVD only, or both at exam 2. Serum P4 $>1 \mathrm{ng} / \mathrm{mL}$ at 35 or 49 DIM (59 and $74 \%$ of LRUD cows, respectively) and its interaction with $\mathrm{PGF}_{2 \alpha}$ were not significant $(P>0.20)$ in these models, consistent with the findings in the HRUD group.

\section{Both HRUD and LRUD Groups}

Treatment of cows with CCFA or $\mathrm{PGF}_{2 \alpha}$ had no effect on time to first service, FSPR, or time to pregnancy $(P>0.20)$, irrespective of $\mathrm{P} 4$ status (Table 5$)$. At $\mathrm{PGF}_{2 \alpha}$ administration at 35 and $49( \pm 3)$ DIM, $26 \%$ of cows had low P4 $(<1 \mathrm{ng} / \mathrm{mL})$ at both times, $20 \%$ had $\mathrm{P} 4>1 \mathrm{ng} / \mathrm{mL}$ at one injection, and $54 \%$ had $\mathrm{P} 4$ consistent with the presence of a corpus luteum at both times. The effect of uterine health status on reproductive performance was variable. The effect of uterine health status on FSPR, accounting for $\mathrm{PGF}_{2 \alpha}$ treatment and retained placenta, is presented in Figure 2. Cows classified as PVD only at exam 1 were 0.6 times as likely as cows having no uterine disease at exam 1 to become pregnant at first insemination $(P<0.01)$. No significant association occurred between CYTO only at exam 1 and FSPR $(P=0.80)$. Median time to first service was not different $(P=0.79)$ among unaffected cows, CYTO only, PVD only (74 d; $95 \%$ CI: $74-75$ ) or both (75 d; 95\% CI: 74-76). Uterine health status had a detrimental effect on time to pregnancy until $300 \mathrm{~d}$ after parturition (Table 6; Figure 3).

Uterine health status at exam 1 and exam 2 was used to classify cows into categories regarding disease progression: unaffected at both examinations, persistent condition, spontaneous recovery (given no effects of $\mathrm{PGF}_{2 \alpha}$ on recovery), or newly affected at exam 2 . For

Table 3. Final multivariable logistic regression model for metritis, accounting for the random effect of herd, in 1,017 Holstein cows with dystocia, twins, or retained placenta enrolled in a clinical trial investigating the effect of ceftiofur crystalline free acid (CCFA) and $\mathrm{PGF}_{2 \alpha}$ on uterine health

\begin{tabular}{|c|c|c|c|c|c|}
\hline Predictor & Class & $\begin{array}{c}\text { Cows }^{1} \\
(\%)\end{array}$ & Coefficient & SE & $P$-value \\
\hline Intercept & & & -0.95 & 0.28 & 0.01 \\
\hline \multirow{2}{*}{ CCFA } & No & 49.9 & Referent & & \\
\hline & Yes & 50.1 & -0.04 & 0.24 & 0.86 \\
\hline \multirow[t]{2}{*}{ Parity } & 1 & 39.3 & Referent & & \\
\hline & $\geq 2$ & 60.7 & -0.97 & 0.23 & $<0.01$ \\
\hline \multirow[t]{2}{*}{ Retained placenta } & No & 61.8 & Referent & & \\
\hline & Yes & 38.2 & 1.33 & 0.23 & $<0.01$ \\
\hline \multirow[t]{4}{*}{ CCFA $\times$ parity } & No $\times 1$ & 19.2 & -0.64 & 0.30 & 0.03 \\
\hline & No $x \geq 2$ & 30.7 & & & \\
\hline & Yes $\times \overline{1}$ & 20.1 & & & \\
\hline & Yes $x \geq 2$ & 30.0 & & & \\
\hline \multirow[t]{4}{*}{$\mathrm{CCFA} \times$ retained placenta } & No $\times$ No & 30.9 & 0.95 & 0.30 & $<0.01$ \\
\hline & No $\times$ Yes & 19.0 & & & \\
\hline & Yes $\times$ No & 30.9 & & & \\
\hline & Yes $\times$ Yes & 19.2 & & & \\
\hline
\end{tabular}

${ }^{1}$ Proportion of cows in each category of each predictor; within each predictor the sum is $100 \%$. 
Table 4. Final multivariable logistic regression model, accounting for the random effect of herd, for presence of purulent vaginal discharge only (PVD only; no simultaneous cytological endometritis) at $35( \pm 3)$ DIM in 956 Holstein cows, classified at high risk of uterine disease (HRUD; having dystocia, twins, or retained placenta), enrolled in a clinical trial investigating the effect of ceftiofur crystalline free acid (CCFA) and $\mathrm{PGF}_{2 \alpha}$ on uterine health

\begin{tabular}{|c|c|c|c|c|c|}
\hline Predictor & Class & $\begin{array}{c}\text { Cows }^{1} \\
(\%)\end{array}$ & $\begin{array}{l}\text { Odds } \\
\text { ratio }\end{array}$ & $\begin{array}{c}95 \% \\
\text { CI }\end{array}$ & $P$-value \\
\hline \multirow[t]{2}{*}{ CCFA } & No & 50.2 & Referent & & \\
\hline & Yes & 49.8 & 0.66 & $0.48-0.89$ & $<0.01$ \\
\hline \multirow[t]{2}{*}{ Metritis } & No & 62.9 & Referent & & \\
\hline & Yes & 37.1 & 3.03 & $2.17-4.17$ & 0.02 \\
\hline \multirow[t]{2}{*}{ Retained placenta } & No & 71.6 & Referent & & \\
\hline & Yes & 28.4 & 1.85 & $1.33-2.56$ & $<0.01$ \\
\hline
\end{tabular}

${ }^{1}$ Proportion of cows in each category of each predictor; within each predictor the sum is $100 \%$.

CYTO, $73 \%(1,481 / 2,022)$ of cows were unaffected at both examinations. Among cows $(\mathrm{n}=400)$ that were classified positive at exam $1,66 \%(\mathrm{n}=262)$ had spontaneously cured and $34 \%(\mathrm{n}=138)$ were persistently affected at exam 2 . Among cows $(\mathrm{n}=1,622)$ unaffected at exam 1, 9\% (n = 141) were diagnosed positive at exam 2. For PVD, $79 \%(1,594 / 2,022)$ of cows were unaffected at both examinations. Among cows $(\mathrm{n}=323)$ that were classified positive at exam 1, 63\% ( $\mathrm{n}=202)$ had spontaneously cured and $37 \%(\mathrm{n}=121)$ were persistently affected at exam 2 . Among cows $(\mathrm{n}=1,699)$ unaffected at exam 1, 6\% $(\mathrm{n}=105)$ were diagnosed positive at exam 2.

Among cows diagnosed with uterine disease at exam 1, those having both CYTO and PVD had the greatest proportion $(60 \%)$ that were persistently affected at exam 2 (CYTO only $=34 \%$, PVD only $=42 \%)$. The risk factors associated with persistent uterine disease were metritis $(P<0.01)$ and being classified as both $(P<0.01)$ at exam 1 . Disease status from exam 1 to exam 2 had no effect on time to first service or FSPR $(P>0.20)$ but was associated with an increase in time to pregnancy (Figure 4).

\section{DISCUSSION}

This is the first large-scale study to simultaneously consider metritis, CYTO, and PVD as outcomes for evaluating the efficacy of treatments and their effects on reproductive performance. It is also one of the largest investigations of risk factors during the postpartum period and of the progression of uterine disease over that period. In herds $(\mathrm{n}=3)$ where all cows (LRUD and HRUD) were enrolled, the proportion of cows in

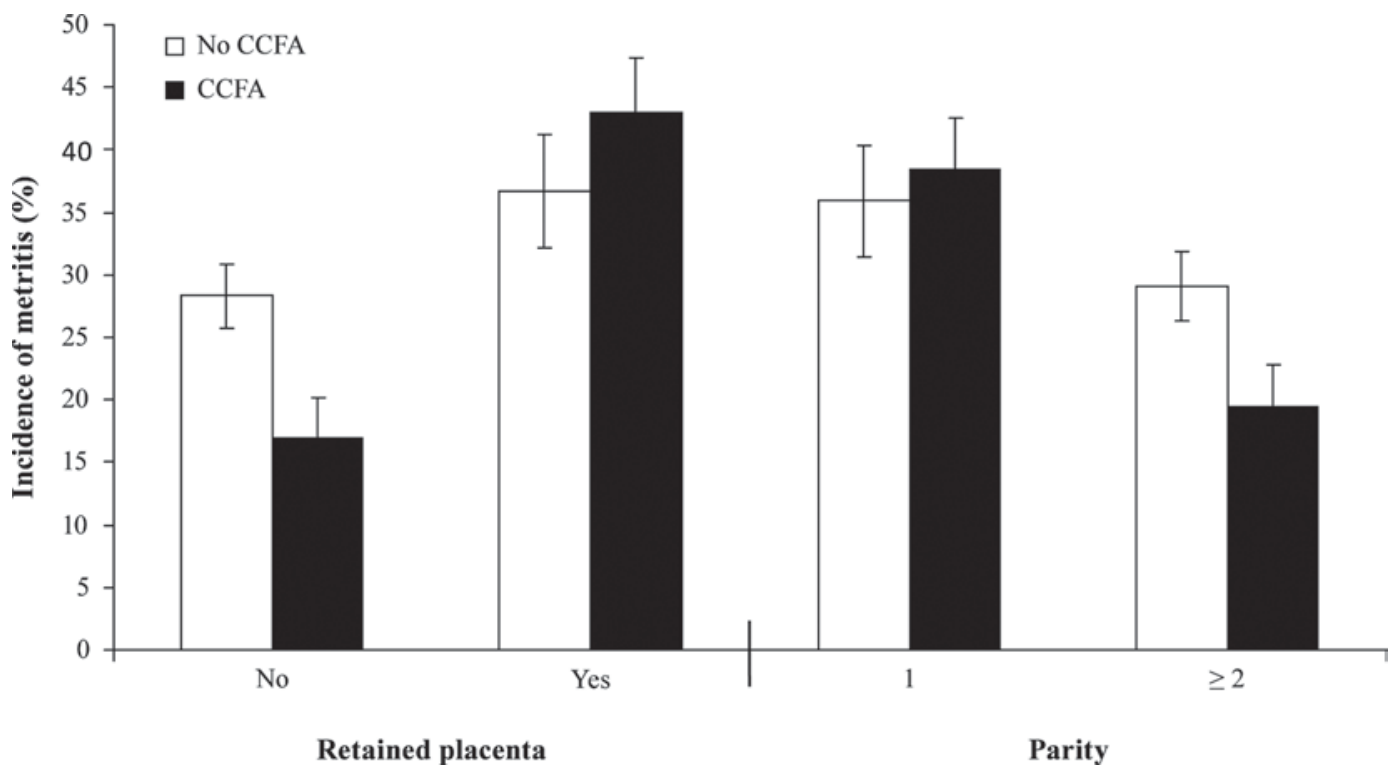

Figure 1. Conditional effects, stratified by retained placenta and parity, of 1 dose of ceftiofur crystalline free acid (CCFA) within $1 \mathrm{~d}$ after calving on the incidence of metritis in 1,017 Holstein cows with dystocia, twins, or retained placenta enrolled in a randomized clinical trial. 


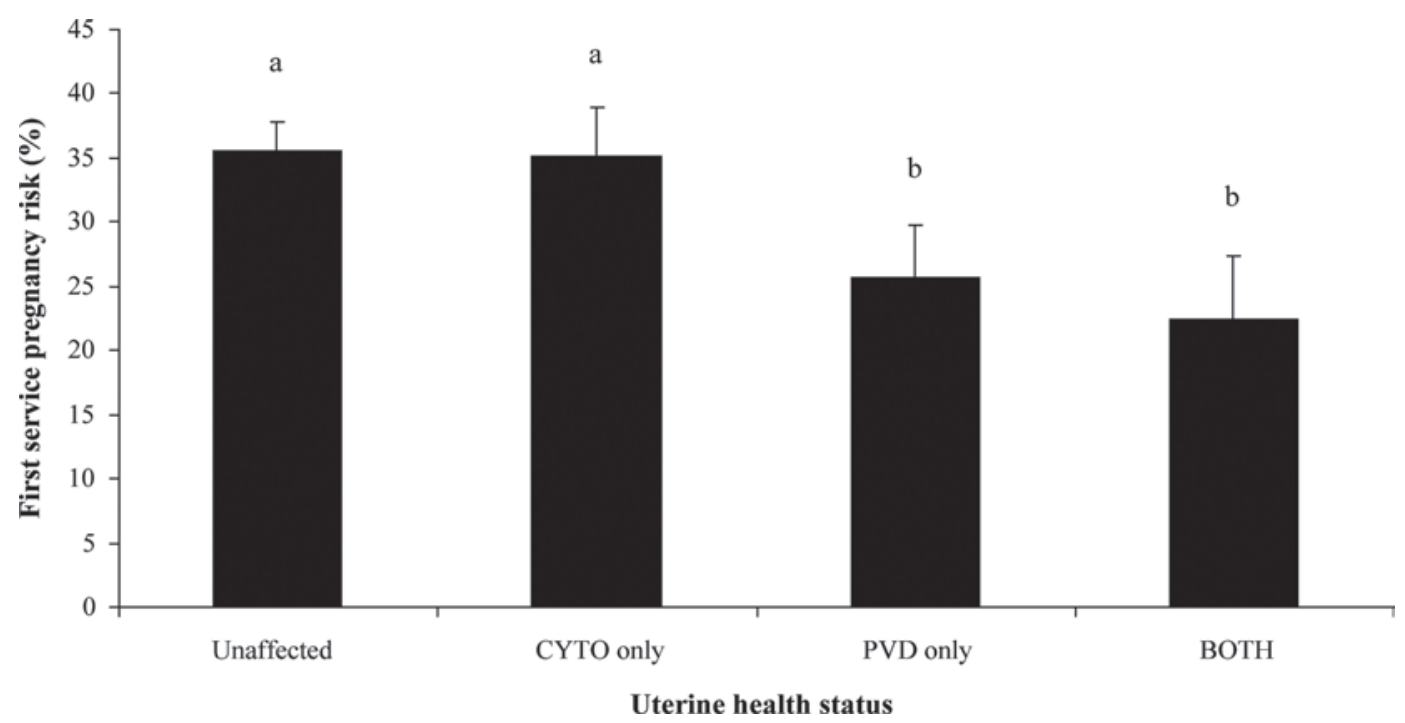

Figure 2. Effect of uterine health status [unaffected; cytological endometritis (CYTO) only; purulent vaginal discharge (PVD) only; or both cytological endometritis and purulent vaginal discharge (both)] at exam 1 (35 \pm 3 DIM) on first-service pregnancy risk (FSPR) in 2,072 Holstein cows enrolled in a clinical trial. Bars with different letters differ $(P<0.05)$.

the HRUD group was 27 to $31 \%$, whereas the proportion of HRUD cows in the entire study was $47 \%$. It is important to consider this when comparing the inci- dence of diseases and conditions in Tables 1 and 2 with other studies. Although the classification of cows in the HRUD group was based on factors (twins, dystocia,

Table 5. Summary of the effects of random assignment to 2 administrations of $\mathrm{PGF}_{2 \alpha}$ at 35 and $49( \pm 3) \mathrm{DIM}$ on reproductive performance of 2,022 Holstein cows from 6 herds ${ }^{1}$

\begin{tabular}{|c|c|c|c|c|c|}
\hline $\begin{array}{l}\text { Serum } \\
\text { progesterone } \\
(\mathrm{ng} / \mathrm{mL})\end{array}$ & $\mathrm{PGF}_{2 \alpha}$ & \multicolumn{2}{|c|}{ Outcome measure } & $\begin{array}{c}95 \% \\
\text { CI }\end{array}$ & $P$-value 2 \\
\hline \multicolumn{6}{|c|}{ Time to first insemination } \\
\hline & & Median (d) & $\mathrm{HR}^{3}$ & & \\
\hline \multirow[t]{2}{*}{$\leq 1^{4}$} & No & 74 & Referent & & \\
\hline & Yes & 74 & 0.90 & $0.83-1.02$ & 0.07 \\
\hline \multirow[t]{4}{*}{$>1^{5}$} & No & 74 & Referent & & \\
\hline & Yes & 74 & 0.92 & $0.84-1.05$ & 0.07 \\
\hline & & Pregnancy & mination & & \\
\hline & & Pregnant $(\%)$ & Odds ratio & & \\
\hline \multirow{2}{*}{$\leq 1^{4}$} & No & 33.9 & Referent & & \\
\hline & Yes & 27.7 & 0.75 & $0.54-1.03$ & 0.08 \\
\hline \multirow[t]{3}{*}{$>1^{5}$} & No & 27.5 & Referent & & \\
\hline & Yes & 30.0 & 1.13 & $0.86-1.49$ & 0.38 \\
\hline & & Mime & ncy ${ }^{6}{ }^{6}$ & & \\
\hline \multirow[t]{2}{*}{$\leq 1^{4}$} & No & 146 & Referent & & \\
\hline & Yes & 156 & 1.04 & $0.94-1.15$ & 0.44 \\
\hline \multirow[t]{2}{*}{$>1^{5}$} & No & 135 & Referent & & \\
\hline & Yes & 133 & 0.97 & $0.91-1.03$ & 0.30 \\
\hline
\end{tabular}

${ }^{1}$ No interaction of the effects of $\mathrm{PGF}_{2 \alpha}$ with the experimental antibiotic treatment in the block of cows with dystocia, twins, or retained placenta (HRUD) that had a factorial treatment assignment of a single dose of long-acting ceftiofur $<24 \mathrm{~h}$ after calving and $\mathrm{PGF}_{2 \alpha}$ at 35 and 49 DIM.

${ }^{2} P$-value for hazard or odds ratio.

${ }^{3}$ Hazard ratio from a Cox proportional hazard model of time to first insemination, to 100 DIM, accounting for herd clustering, $\mathrm{HR}<1$ indicates a reduced instantaneous relative risk of insemination; HR $>1$ indicates an increased instantaneous relative risk of insemination.

${ }^{4}$ At both d 35 and 49 after parturition.

${ }^{5}$ At least once at d 35 or 49 after parturition.

${ }^{6}$ Hazard ratio from a Cox proportional hazard model of time to pregnancy, to 300 DIM, accounting for herd clustering, $\mathrm{HR}<1$ indicates a reduced instantaneous relative risk of pregnancy; HR $>1$ indicates an increased instantaneous relative risk of pregnancy. 
Table 6. Final Cox proportional hazard model of time to pregnancy (by $300 \mathrm{~d}$ after parturition) in 2,072 Holstein cows enrolled in a clinical trial investigating the effect of $\mathrm{PGF}_{2 \alpha}$ on uterine health, and examined for uterine health status 35 DIM $( \pm 3$; exam 1$)$

\begin{tabular}{|c|c|c|c|c|c|c|}
\hline Predictor & Class & Coefficient & $\mathrm{SE}$ & $\mathrm{HR}^{1}$ & $95 \% \mathrm{CI}$ & $P$-value \\
\hline \multirow[t]{2}{*}{$\mathrm{PGF}_{2 \alpha}$} & No & Referent & & & & \\
\hline & Yes & -0.01 & 0.01 & 0.99 & $0.96-1.02$ & 0.50 \\
\hline \multirow{4}{*}{$\begin{array}{l}\text { Uterine health } \\
\text { status }^{2}\end{array}$} & Unaffected & Referent & & & & \\
\hline & CYTO only & -0.21 & 0.03 & 0.81 & $0.76-0.86$ & $<0.01$ \\
\hline & PVD only & -0.32 & 0.08 & 0.72 & $0.62-0.84$ & $<0.01$ \\
\hline & $\begin{array}{l}\text { Both CYTO } \\
\text { and PVD }\end{array}$ & -0.54 & 0.08 & 0.59 & $0.50-0.68$ & $<0.01$ \\
\hline \multirow{2}{*}{ Parity } & 1 & Referent & & & & \\
\hline & $\geq 2$ & -0.26 & 0.01 & 0.77 & $0.75-0.79$ & $<0.01$ \\
\hline \multirow[t]{2}{*}{$\mathrm{CL}^{3} \leq 63 \mathrm{~d}$} & $\bar{N}_{0}$ & Referent & & & & \\
\hline & Yes & 0.21 & 0.09 & 1.23 & $1.03-1.47$ & 0.02 \\
\hline
\end{tabular}

${ }^{1}$ Hazard ratio; $\mathrm{HR}<1$ indicates a reduced instantaneous relative risk of pregnancy; $\mathrm{HR}>1$ indicates an increased instantaneous relative risk of pregnancy.

${ }^{2} \mathrm{CYTO}=$ cytological endometritis; PVD $=$ purulent vaginal discharge.

${ }^{3}$ Corpus luteum (serum progesterone $>1 \mathrm{ng} / \mathrm{mL}$ ) at least once before 63 DIM.

and retained placenta) previously reported to increase the risk of developing uterine disease (Gröhn et al., 1990; Correa et al., 1993; LeBlanc et al., 2002a), these are not the only determinants of uterine disease. It is noteworthy that the incidence of metritis in the LRUD group was $12.0 \%$, not zero. In the HRUD group, the incidence of metritis was $28 \%$. The rationale for blocking cows (LRUD or HRUD) on these risk factors was to test the benefit of using antibiotic therapy in a targeted population of cows affected by factors increasing uterine

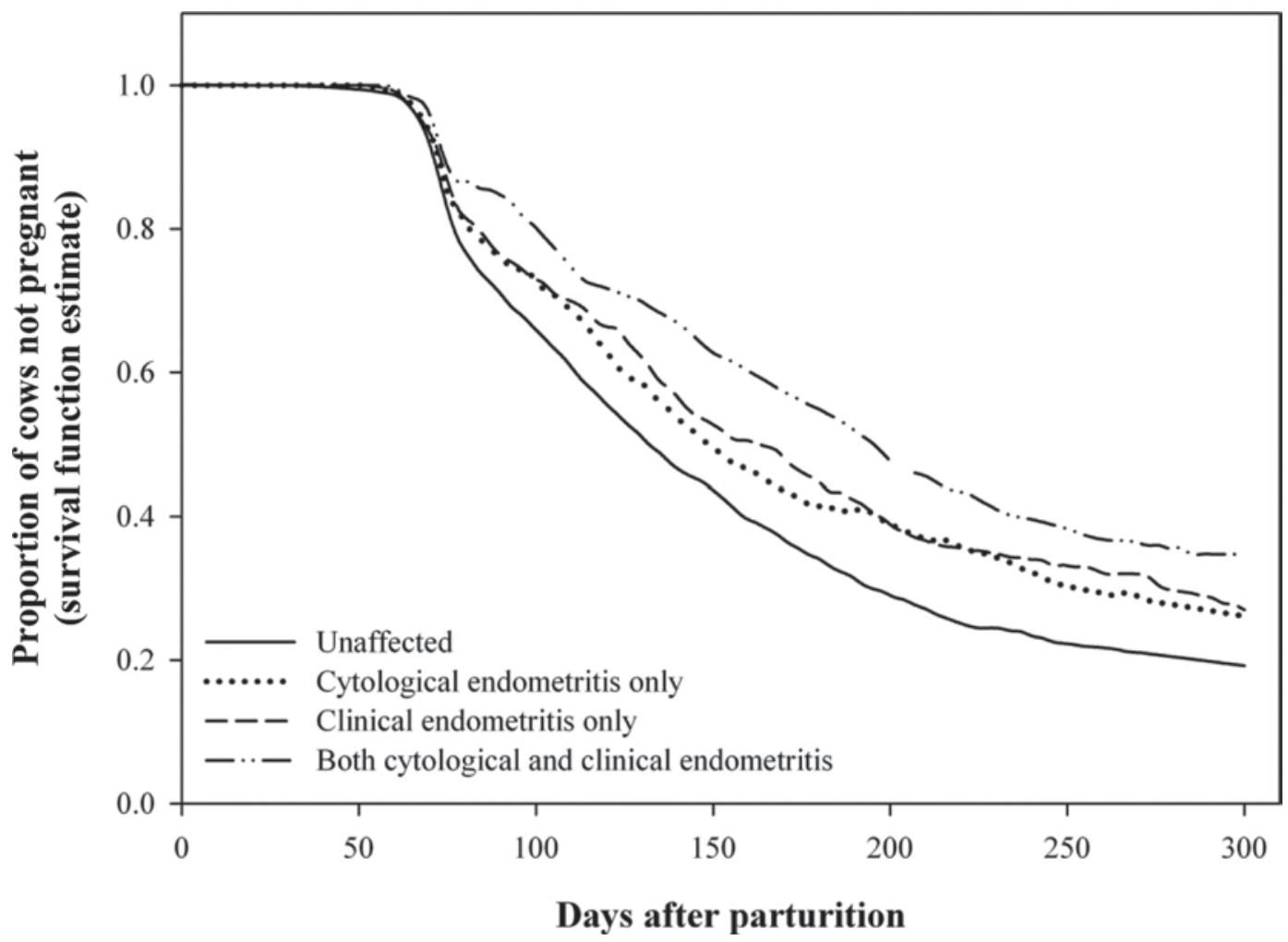

Figure 3. Survival curves for time to pregnancy up to $300 \mathrm{~d}$ after parturition in 2.072 Holstein cows in 6 herds, according to their uterine health status at 35 DIM ( \pm 3 ; exam 1 ): unaffected (UNAF; $n=1493)$; cytological endometritis (CYTO) only ( $\geq 6 \%$ polymorphonuclear cells; $\mathrm{n}=260$ ); purulent vaginal discharge (PVD) only (mucopurulent or purulent vaginal discharge; $\mathrm{n}=188$ ); or both CYTO and PVD (both; $\mathrm{n}=$ 131). Median time to pregnancy (95\% CI) was 132 d (127-137), 148 d (139-157), 156 d (144-168), and 195 d (174-216) for UNAF, CYTO only, PVD only, and both, respectively. 


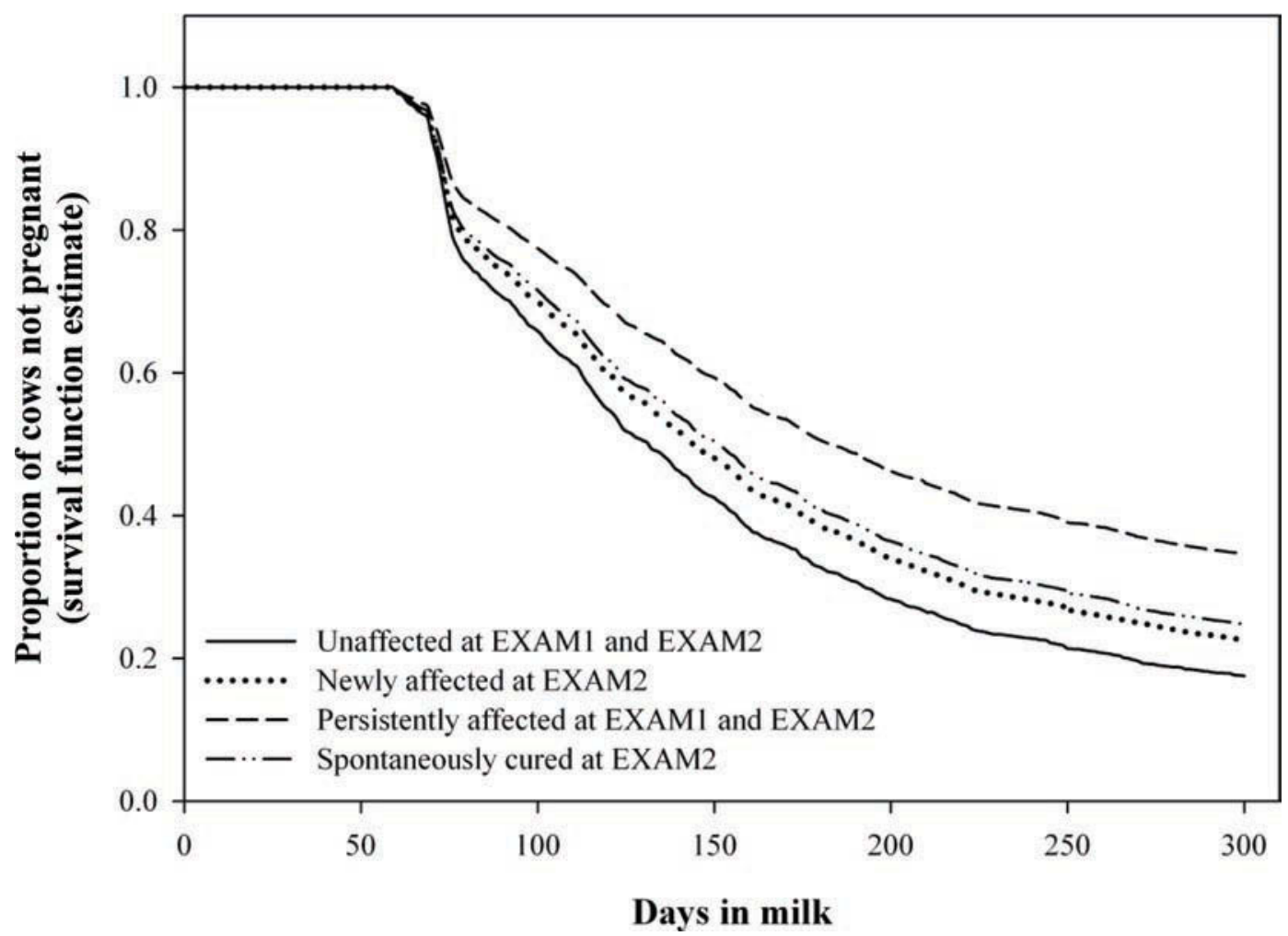

Figure 4. Survival curves for time to pregnancy up to $300 \mathrm{~d}$ after parturition in 2,022 Holstein cows, according to uterine health status at 35 $( \pm 3$; exam 1$)$ and 56 DIM ( \pm 3 ; exam 2$)$ : unaffected at exam 1 and exam 2 (UNAF; $\mathrm{n}=1274)$; newly affected at exam 2 (new; $\mathrm{n}=173)$; persistently affected at exam 1 and exam 2 (PERS; $\mathrm{n}=240$ ); or spontaneously cured at exam 2 (cure; $\mathrm{n}=335)$. Median time to pregnancy $(95 \%$ confidence interval) was $132 \mathrm{~d}$ (126-138), $144 \mathrm{~d}$ (125-163), $180 \mathrm{~d}$ (171-189), and $150 \mathrm{~d}$ (142-158) for UNAF, new, PERS, and cure, respectively.

contamination. The hypothesis was that such cows were likely to be infected with $E$. coli, that early treatment of this infection would reduce the risk of progression to metritis, and that ceftiofur would be a suitable antibiotic to reduce the load of uterine pathogens (Drillich et al., 2006a).

Interestingly, the proportion of cows classified as having a $\mathrm{BCS} \leq 2.75$ was much greater in the HRUD group than in the LRUD group. Although these groups are not directly comparable because of the study design, this finding suggests that cows in HRUD group were generally thinner, which may be indicative of a poor dry period and reduced feed intake.

The effect of CCFA therapy for preventing metritis was evaluated in 2 steps to evaluate its overall effect (model without 2-way interaction) and the potential for conditional effects (model with 2-way interactions). As used in the present experiment, CCFA did not decrease the incidence of metritis overall. Although the design was to examine the effect of antibiotic treatment on metritis or endometritis among cows with any of $\mathrm{RP}$, twins, or dystocia, interactions in the final multivariable model indicated conditional effects. Cows with dystocia or twins that did not have RP, and cows that had 1 of these 3 conditions and were in parity $\geq 2$ that received CCFA had a reduced incidence of metritis. These effects suggest that the experimental hypothesis should not be discarded but explored further in future randomized clinical trials designed to test the effects of antimicrobial therapy for prevention of metritis in these sub-populations. The lack of a significant overall effect of metaphylactic antibiotic treatment despite achieving the planned sample size for detection of this main effect might be related to the dose or pharmacology of the product used. It is unknown if the dose and single administration of CCFA used in this study were sufficient to reach and maintain antimicrobial concentration in the endometrium or uterine lumen to suppress bacterial pathogens. Evidence from other studies suggests that ceftiofur sodium and ceftiofur hydrochloride have a spectrum of activity that covers the common and important uterine contaminants soon after parturition, such as E. coli, F. necrophorum, P. melaninogenicus, and A. pyogenes (Bondurant, 1999; Okker et al., 2002; Drillich et al., 2006a). Recent studies report conflicting evidence about whether certain genomic or phenotypic groups of E. coli may be associated with uterine disease in cattle (Silva et al., 2009; Sheldon et al., 2010), al- 
though no data indicate that the minimum inhibitory concentration of antibiotic differs among these strains. Alternatively, other variables such as innate immune function in the uterus may be more important than the level of bacterial contamination in the early postpartum period (Sheldon et al., 2009a). Cows in the HRUD group that did not have RP may have experienced a lower burden of uterine contamination than cows that had $\mathrm{RP}$; if so, the dose of CCFA may have been sufficient to reduce the uterine pathogen load, and thereby decrease the incidence of metritis. The interaction of CCFA with parity is more difficult to explain. Multiparous cows have a larger uterus, which might interfere with the draining of lochia (Marion et al., 1968). In some multiparous cows, antibiotic treatment may help to shift the balance between infection and host response.

Although the use of CCFA in HRUD cows did not reduce the incidence of CYTO, it did significantly decrease the probability of PVD at exam 1. Uterine diseases are associated with infection with $E$. coli in the first week after calving (Dohmen et al., 2000; Zerbe et al., 2001), and PVD is associated with A. pyogenes (Bondurant, 1999; Williams et al., 2005). As used, CCFA may have decreased the uterine load of bacteria such as A. pyogenes, but might not have sufficiently reduced numbers of other bacteria that are associated with metritis earlier in the postpartum period, such as E. coli. This may be explained by the higher minimum inhibitory concentration of $E$. coli compared with that of A. pyogenes (Sheldon et al., 2004). Because the risk factors associated with CYTO are linked to energy balance and immune function (Sheldon et al., 2009a; Dubuc et al., 2010b), it is not surprising that antimicrobial therapy had no direct effect on it, in contrast to PVD. The relationship between uterine pathogen load and endometrial inflammation has been described (Santos et al., 2008) but is not well understood, and it has been suggested that endometrial inflammation may persist after bacterial pathogens are no longer detected (Sheldon et al., 2009a,b).

A greater proportion of cows in the HRUD group than the LRUD group had metritis and PVD but not CYTO. Cytological endometritis and PVD have been shown to be distinct because they have separate risk factors and effects on reproduction (Dubuc et al., 2010a). It was expected that cows with RP, twins, or dystocia would have higher incidences of metritis and PVD because these diseases are associated with reproductive tract trauma (Dubuc et al., 2010b; Potter et al., 2010). It was surprising that the prevalence of CYTO was very similar between LRUD and HRUD groups, for reasons that remain unclear. Endometrial inflammation may not necessarily be linked to bacterial pathogen load but to factors such as regulation of the immune response
(Herath et al., 2009), which may not be captured in classifications based on crude risk factors at calving (HRUD and LRUD).

Data on the effect of $\mathrm{PGF}_{2 \alpha}$ on uterine health and reproduction are conflicted (Burton and Lean, 1995; LeBlanc et al., 2002b; Galvão et al., 2009). Reported benefits of $\mathrm{PGF}_{2 \alpha}$ are probably linked to an effect of estrus synchronization, because most of these studies did not consider uterine health status as a predictor or an outcome (Burton and Lean, 1995). Among investigations of uterine health, none until now considered CYTO and PVD simultaneously. In the present trial, $\mathrm{PGF}_{2 \alpha}$ treatment at $35 \mathrm{~d}$ and 49 DIM did not influence uterine health at exam 2 in either the LRUD or HRUD groups, accounting for uterine health status at exam 1. Surprisingly, this lack of effect was not modulated by the presence of a corpus luteum (serum $\mathrm{P} 4>1 \mathrm{ng} /$ $\mathrm{mL}$ ) at $\mathrm{PGF}_{2 \alpha}$ administration. This finding is consistent with a recent study that investigated the effect of $\mathrm{PGF}_{2 \alpha}$ for treatment of CYTO (Galvão et al., 2009). In the present data, $\mathrm{PGF}_{2 \alpha}$ treatment had no effect on time to first service, FSPR, or time to pregnancy, again independent of whether cows were at high or low risk of uterine disease. None of the variables considered (CCFA, RP, dystocia, twins, metritis, parity, progesterone status at $21,35,49$ or 63 DIM, BCS at parturition and 63 DIM, and uterine health status at 35 and 56 DIM) identified a sub-population in which $\mathrm{PGF}_{2 \alpha}$ was associated with an improvement of FSPR or pregnancy rate (hazard ratio). This is surprising and different from another study, which found an increase in FSPR in all cows treated with $\mathrm{PGF}_{2 \alpha}$, and an increased pregnancy rate in cows with a body condition score $\leq 2.5$ treated with $\mathrm{PGF}_{2 \alpha}$ (Galvão et al., 2009). In that study, the $\mathrm{PGF}_{2 \alpha}$ treatment group received $\mathrm{PGF}_{2 \alpha}$ at 21,35 , and 49 DIM and the voluntary waiting period was $49 \mathrm{~d}$, confounding possible uterine health and estrus synchronization effects on FSPR and pregnancy rate (Galvão et al., 2009). In the present study, to assess putative effects of $\mathrm{PGF}_{2 \alpha}$ on reproductive tract health separately from effects of estrus synchronization, cows in the $\mathrm{PGF}_{2 \alpha}$ group were not bred using $\mathrm{PGF}_{2 \alpha}$ treatments as estrus or ovulation synchronization tools, which could confound the association of $\mathrm{PGF}_{2 \alpha}$ treatment with reproductive performance.

The hypothesis was that inducing estrus with $\mathrm{PGF}_{2 \alpha}$ should lead to evacuation of uterine contaminants and improvement of uterine health (Kasimanickam et al., 2005b). The present study was not designed to document luteolysis after treatment with $\mathrm{PGF}_{2 \alpha}$, and does not offer a mechanistic explanation of the lack of observed $\mathrm{PGF}_{2 \alpha}$ of $\mathrm{PGF}_{2 \alpha}$ on uterine health. Nevertheless, in this very large scale field study in multiple herds, $\mathrm{PGF}_{2 \alpha}$ treatment was not associated with the 
prevalence of PVD or CYTO 1 wk after 2 injections of $\mathrm{PGF}_{2 \alpha}$, or with the economically relevant outcome of time to pregnancy in cows with or without uterine disease at $5 \mathrm{wk}$ postpartum. Other studies found similar results for CYTO following 3 injections of $\mathrm{PGF}_{2 \alpha}$ given every other week (Galvão et al., 2009) or for PVD after a single injection of $\mathrm{PGF}_{2 \alpha}$ (LeBlanc et al., 2002b). It is likely that $\mathrm{PGF}_{2 \alpha}$ treatment induces estrus in cows with a responsive corpus luteum, but under the conditions of this study, $\mathrm{PGF}_{2 \alpha}$ treatment did not result in an observed cytological, clinical, or reproductive performance benefit.

Surprisingly, a statistical trend of detrimental effect of $\mathrm{PGF}_{2 \alpha}$ treatment on risk of pregnancy at first insemination was noted (Table 5). Although a similar finding has been reported previously (LeBlanc et al., 2002b), it remains unclear why cows treated with $\mathrm{PGF}_{2 \alpha}$ during the postpartum period would have decreased fertility at first insemination. A detrimental effect on ovarian and immune functions may be implied but further research is needed to better understand this phenomenon.

As expected, uterine health status was associated with reproductive performance, which is consistent with similar studies (LeBlanc et al., 2002a; Gilbert et al., 2005; Barlund et al., 2008). Endometrial inflammation is detrimental to embryo survival (Hill and Gilbert, 2008), and previous studies have reported that cows with CYTO had reduced FSPR (Gilbert et al., 2005; Barlund et al., 2008). The lack of a negative effect of CYTO on FSPR in the present trial could be explained by the differentiation between CYTO only and the "both" categories, whereas only cows with CYTO were considered by Barlund et al. (2008). Moreover, little information on reproductive management was presented in other reports (Gilbert et al., 2005; Barlund et al., 2008), which makes comparison with the present study difficult. Nonetheless, it was surprising that CYTO had no effect on FSPR, but was detrimental to pregnancy rate in the longer term, with an increase of $16 \mathrm{~d}$ in median time to pregnancy compared with cows with neither CYTO nor PVD. Similarly, other studies found that cows with CYTO had an increased time to pregnancy of 30 to $88 \mathrm{~d}$ (Gilbert et al., 2005; Barlund et al., 2008). In the present study, cows having PVD only and both PVD and CYTO had an increased time to pregnancy of 24 and $63 \mathrm{~d}$, respectively, compared with cows with neither CYTO nor PVD. The effect of PVD was similar to an increase of $34 \mathrm{~d}$ reported by LeBlanc et al. (2002a). Unfortunately, in all these previous studies, it was impossible to determine which cows were affected by both PVD and CYTO, because they did not use CYTO and PVD diagnostic techniques simultaneously (LeBlanc et al., 2002a; Gilbert et al., 2005; Barlund et al., 2008).
Cows were classified according to uterine disease status at both exam 1 and exam 2 . At exam 2, the proportion of cows that experienced spontaneous cure of the form of uterine disease with which they were affected at exam 1, was $66 \%$ and $63 \%$ for CYTO and PVD, respectively. This is consistent with another study investigating cows affected by PVD, which reported $75 \%$ spontaneous cure (Gautam et al., 2010), albeit over an interval of 1 mo. This proportion of cure for PVD in both studies is high and may be reflective of the natural process of uterine involution in the postpartum period. However, the study by Gautam et al. (2010) did not find any detrimental effect on subsequent reproductive performance for cows that spontaneously cured. This is different from the present study, which found an increase of $18 \mathrm{~d}$ in median time to pregnancy in cows that cured between exam 1 and exam 2 relative to those unaffected by any form of uterine disease at both examinations. In fact, cows that spontaneously cured between exam 1 and exam 2 had similarly increased median time to pregnancy as cows found negative at exam 1 and newly diagnosed positive at exam 2 . These data suggest that although spontaneous cure happens in a large proportion of cows, these cows still experience reduced subsequent reproductive performance. Thus, if the definition of a healthy cow is based on subsequent time to pregnancy, cows should resolve uterine inflammation and vaginal discharge before 35 DIM.

Unfortunately, not all cows with uterine disease at exam 1 spontaneously cured between exam 1 and exam 2 . The proportion of cows persistently affected was 35 and $37 \%$ for CYTO and PVD, respectively. For PVD, this is greater than the $25 \%$ persistence in a comparable study, but with a 2-wk longer interval between examinations (Gautam et al., 2010). These persistently affected cows had an increase in median time to pregnancy of 48 d compared with cows unaffected by CYTO or PVD. The group with both PVD and CYTO had the greatest proportion $(60 \%)$ of cows that were found positive at exam 1 and that remained positive at exam 2. Future research should focus on finding effective therapies for cows diagnosed with both CYTO and PVD; this group may benefit the most from these therapies, because their reproductive performance is most affected.

Among cows found negative at exam 1, 9 and $6 \%$ were found positive at exam 2 for CYTO and PVD, respectively. This is similar to $11 \%$ for apparent new PVD reported by Gautam et al. (2010). Intuitively, cows should cure from CYTO and PVD over time and should not become newly affected or relapse. However, it is unknown what induces these apparently newly affected cows. It could be speculated that the procedures at exam 1 may have caused iatrogenic uterine disease in some cows. Other hypotheses are that these cows were 
false negative at exam 1 or that spontaneous occurrence of uterine disease occurs later in the postpartum period. It has been reported that bacterial infection can re-occur after the uterus has become sterile in the postpartum period (Griffin et al., 1974a,b), which may lead to endometrial inflammation or PVD. This may suggest that this is a naturally occurring process, but further research is needed.

\section{CONCLUSIONS}

The administration of CCFA soon after parturition in cows at high risk of uterine disease conditionally reduced the incidence of metritis, particularly among cows with dystocia or twins but without RP, and reduced the prevalence of PVD at 35 DIM. These findings support the concept of decreasing the uterine bacterial contamination load in the early postpartum period to prevent subsequent uterine disease. Treatment of cows with $\mathrm{PGF}_{2 \alpha}$ at 35 and $49 \mathrm{~d}$ after parturition had no effect on uterine health or subsequent reproductive performance when not used for estrus synchronization. Herd-specific reassessment of the prevalence, effect, and approach to treatment of reproductive tract disease before breeding is warranted. Cytological endometritis and PVD had additive detrimental effects on subsequent reproduction. Spontaneous cure of both conditions between 5 and 8 wk postpartum was common but the conditions were still detrimental, and failure to cure was associated with a substantial reduction in pregnancy rate in affected individuals.

\section{ACKNOWLEDGMENTS}

This project was financially supported by Pfizer Animal Health (Kirkland, Québec, Canada). The authors thank the farmers, veterinarians, and technical staff for their participation.

\section{REFERENCES}

Barlund, C. S., T. D. Carruthers, C. L. Waldner, and C. W. Palmer. 2008. A comparison of diagnostic techniques for postpartum endometritis in dairy cattle. Theriogenology 69:714-723.

Bondurant, R. H. 1999. Inflammation in the bovine female reproductive tract. J. Anim. Sci. 77:101-110.

Burton, N. R., and I. J. Lean. 1995. Investigation by meta-analysis of the effect of prostaglandin F2 $\alpha$ administered post partum on the reproductive performance of dairy cattle. Vet. Rec. 136:90-94.

Chenault, J. R., J. F. McAllister, S. T. Chester Jr., K. J. Dame, F. M. Kausche, and E. J. Robb. 2004. Efficacy of ceftiofur hydrochloride sterile suspension administered parenterally for the treatment of acute postpartum metritis in dairy cows. J. Am. Vet. Med. Assoc. 224:1634-1639.

Correa, M. T., H. Erb, and J. Scarlett. 1993. Path analysis for seven postpartum disorders of Holstein cows. J. Dairy Sci. 76:13051312 .
Dohmen, M. J. W., K. Joop, A. Sturk, P. E. J. Bols, and J. A. C. M. Lohuis. 2000. Relationship between intra-uterine bacterial contamination, endotoxin levels and the development of endometritis in postpartum cows with dystocia or retained placenta. Theriogenology 54:1019-1032.

Dohoo, I., W. Martin, and H. Stryhn. 2003. Veterinary Epidemiologic Research. 1st ed. AVC Inc., Charlottetown, Prince Edward Island, Canada.

Drillich, M., S. Arlt, S. Kersting, A. A. Bergwerff, P. Scherpenisse, and W. Heuwieser. 2006a. Ceftiofur derivatives in serum, uterine tissues, cotyledons, and lochia after fetal membrane retention. J. Dairy Sci. 89:3431-3438.

Drillich, M., O. Beetz, A. Pfützner, M. Sabin, H. J. Sabin, P. Kutzer, H. Nattermann, and W. Heuwieser. 2001. Evaluation of a systemic antibiotic treatment of toxic puerperal metritis in dairy cows. J. Dairy Sci. 84:2010-2017.

Drillich, M., A. Pfützner, H. J. Sabin, M. Sabin, and W. Heuwieser. 2003. Comparison of two protocols for the treatment of retained fetal membranes in dairy cattle. Theriogenology 59:951-960.

Drillich, M., U. Reichert, M. Mahlstedt, and W. Heuwieser. 2006b. Comparison of two strategies for systemic antibiotic treatment of dairy cows with retained fetal membranes: Preventive vs. selective treatment. J. Dairy Sci. 89:1502-1508.

Dubuc, J., T. F. Duffield, K. E. Leslie, J. S. Walton, and S. J. LeBlanc. 2010a. Definitions and diagnosis of postpartum endometritis in dairy cows. J. Dairy Sci. 93:5225-5234. doi:10.3168/jds.20103428.

Dubuc, J., T. F. Duffield, K. E. Leslie, J. S. Walton, and S. J. LeBlanc. 2010b. Risk factors for postpartum uterine diseases in dairy cows. J. Dairy Sci. 93:5764-5771. doi:10.3168/jds.2010-3429.

Elliott, L., K. J. McMahon, H. T. Gier, and G. B. Marion. 1968. Uterus of the cow after parturition: Bacterial content. Am. J. Vet. Res. 29:77-81.

Ferguson, J. D., D. T. Galligan, and N. Thomsen. 1994. Principal descriptors of body condition score in Holstein cows. J. Dairy Sci. 77:2695-2703.

Földi, J., M. Kulcsár, A. Pécsi, B. Huyghe, C. d. Sa, J. A. C. M. Lohuis, P. Cox, and G. Huszenicza. 2006. Bacterial complications of postpartum uterine involution in cattle. Anim. Reprod. Sci. 96:265-281.

Galvão, K. N., M. Frajblat, S. B. Brittin, W. R. Butler, C. L. Guard, and R. O. Gilbert. 2009. Effect of prostaglandin F2 $\alpha$ on subclinical endometritis and fertility in dairy cow. J. Dairy Sci. 92:49064913.

Gautam, G., T. Nakao, K. Koike, S. T. Long, M. Yusuf, R. M. S. B. K. Ranasinghe, and A. Hayashi. 2010. Spontaneous recovery or persistence of postpartum endometritis and risk factors for its persistence in Holstein cows. Theriogenology 73:168-179.

Gilbert, R. O., S. T. Shin, C. L. Guard, H. N. Erb, and M. Frajblat. 2005. Prevalence of endometritis and its effects on reproductive performance of dairy cows. Theriogenology 64:1879-1888.

Griffin, J. F. T., P. J. Hartigan, and W. R. Nunn. 1974a. Non-specific uterine infection and bovine fertility: I. Infection patterns and endometritis during the first seven weeks post-partum. Theriogenology 1:91-106.

Griffin, J. F. T., P. J. Hartigan, and W. R. Nunn. 1974b. Non-specific uterine infection and bovine fertility: II. Infection patterns and endometritis before and after service. Theriogenology 1:107-114.

Gröhn, Y. T., S. W. Eicker, V. Ducrocq, and J. A. Hertl. 1998. Effect of diseases on the culling of Holstein dairy cows in New York State. J. Dairy Sci. 81:966-978.

Gröhn, Y. T., H. N. Erb, C. E. McCulloch, and H. S. Saloniemi. 1990. Epidemiology of reproductive disorders in dairy cattle: Associations among host characteristics, disease and production. Prev. Vet. Med. 8:25-39.

Herath, S., S. T. Lilly, N. R. Santos, R. O. Gilbert, L. Goetze, C. E. Bryant, J. O. White, J. Cronin, and I. M. Sheldon. 2009. Expression of genes associated with immunity in the endometrium of cattle with disparate postpartum uterine disease and fertility. Reprod. Biol. Endocrinol. 7:55-68. 
Hibbard, B., E. J. Robb, S. T. Chester Jr., K. J. Dame, J. F. Boucher, and G. R. Alaniz. 2002a. Dose determination and confirmation of a long-acting formulation of ceftiofur (ceftiofur crystalline free acid) administered subcutaneously for the treatment of bovine respiratory disease. J. Vet. Pharmacol. Ther. 25:175-180.

Hibbard, B., E. J. Robb, S. T. Chester Jr., K. J. Dame, W. W. Moseley, and W. L. Bryson. 2002b. Dose determination and confirmation for ceftiofur crystalline-free acid administered in the posterior aspect of the ear for control and treatment of bovine respiratory disease. Vet. Ther. 3:22-30.

Hill, J., and R. Gilbert. 2008. Reduced quality of bovine embryos cultured in media conditioned by exposure to an inflamed endometrium. Aust. Vet. J. 86:312-316.

Kasimanickam, R., T. F. Duffield, R. A. Foster, C. J. Gartley, K. E. Leslie, J. S. Walton, and W. H. Johnson. 2004. Endometrial cytology and ultrasonography for the detection of subclinical endometritis in postpartum dairy cows. Theriogenology 62:9-23.

Kasimanickam, R., T. F. Duffield, R. A. Foster, C. J. Gartley, K. E Leslie, J. S. Walton, and W. H. Johnson. 2005a. A comparison of the cytobrush and uterine lavage techniques to evaluate endometrial cytology in clinically normal postpartum dairy cows. Can. Vet. J. 46:255-259.

Kasimanickam, R., T. F. Duffield, R. A. Foster, C. J. Gartley, K. E. Leslie, J. S. Walton, and W. H. Johnson. 2005b. The effect of a single administration of cephapirin or cloprostenol on the reproductive performance of dairy cows with subclinical endometritis. Theriogenology 63:818-830.

LeBlanc, S. J. 2008. Postpartum uterine disease and dairy herd reproductive performance: A review. Vet. J. 176:102-114.

LeBlanc, S. J., T. F. Duffield, K. E. Leslie, K. G. Bateman, G. P. Keefe, J. S. Walton, and W. H. Johnson. 2002a. Defining and diagnosing postpartum clinical endometritis and its impact on reproductive performance in dairy cows. J. Dairy Sci. 85:2223-2236.

LeBlanc, S. J., T. F. Duffield, K. E. Leslie, K. G. Bateman, G. P. Keefe, J. S. Walton, and W. H. Johnson. 2002b. The effect of treatment of clinical endometritis on reproductive performance in dairy cows. J. Dairy Sci. 85:2237-2249.

Marion, G. B., J. S. Norwood, and H. T. Gier. 1968. Uterus of the cow after parturition: Factors affecting regression. Am. J. Vet. Res. 29:71-75.

Martin, J. L., K. A. Vonnahme, D. C. Adams, G. P. Lardy, and R. N. Funston. 2007. Effects of dam nutrition on growth and reproductive performance of heifer calves. J. Anim. Sci. 85:841-847.

McDougall, S., R. Macaulay, and C. Compton. 2007. Association between endometritis diagnosis using a novel intravaginal device and reproductive performance in dairy cattle. Anim. Reprod. Sci. 99:9-23.

McLaughlin, C., C. LaGrow, C. Daugherty, E. Stanisiewski, and M. Lucas. 2010. Control of acute postpartum metritis in lactating dairy cows at high risk of developing metritis following dystocia, stillbirth, twinning and/or retained placenta/fetal membranes with ceftiofur crystalline free acid sterile suspension (CCFA-SS). J. Dairy Sci. 93(E-Suppl. 1):407. (Abstr.)

Noakes, D. E., L. Wallace, and G. R. Smith. 1991. Bacterial flora of the uterus of cows after calving on two hygienically contrasting farms. Vet. Rec. 128:440-442.

Okker, H., E. J. Schmitt, P. L. A. M. Vos, P. Scherpenisse, A. A. Bergwerff, and F. H. Jonker. 2002. Pharmacokinetics of ceftiofur in plasma and uterine secretions and tissues after subcutaneous postpartum administration in lactating dairy cows. J. Vet. Pharmacol. Ther. 25:33-38.

Overton, M., and J. Fetrow. 2008. Economics of postpartum uterine health. Pages 39-43 in Proc. Dairy Cattle Reprod. Counc. Conv., Omaha, NE. Dairy Cattle Reproductive Council, Hartland, WI
Potter, T. J., J. Guitan, J. Fishwick, P. J. Gordon, and I. M. Sheldon. 2010. Risk factors for clinical endometritis in postpartum dairy cattle. Theriogenology 74:127-134.

Risco, C. A., and J. Hernandez. 2003. Comparison of ceftiofur hydrochloride and estradiol cypionate for metritis prevention and reproductive performance in dairy cows affected with retained fetal membranes. Theriogenology 60:47-58.

Santos, N.R., K.N Galvão, S.B. Brittin, and R.O. Gilbert. 2008. The significance of uterine $E$. coli infection in the early postpartum period of dairy cows. Reprod. Domest. Anim. 43(Suppl.1):63. (Abstr.)

Sheldon, I. M., M. Bushnell, J. Montgomery, and A. N. Rycroft. 2004. Minimum inhibitory concentrations of some antimicrobial drugs against bacteria causing uterine infections in cattle. Vet. Rec. 155:383-387.

Sheldon, I. M., J. Cronin, L. Goetze, G. Donofrio, and H.-J. Schuberth. 2009a. Defining postpartum uterine disease and the mechanisms of infection and immunity in the female reproductive tract in cattle. Biol. Reprod. 81:1025-1032.

Sheldon, I. M., G. S. Lewis, S. LeBlanc, and R. O. Gilbert. 2006. Defining postpartum uterine disease in cattle. Theriogenology 65:1516-1530.

Sheldon, I. M., D. E. Noakes, A. N. Rycroft, and H. Dobson. 2002a. Effect of postpartum manual examination of the vagina on uterine bacterial contamination in cows. Vet. Rec. 151:531-534.

Sheldon, I. M., D. E. Noakes, A. N. Rycroft, D. U. Pfeiffer, and H. Dobson. 2002b. Influence of uterine bacterial contamination after parturition on ovarian dominant follicle selection and follicle growth and function in cattle. Reproduction 123:837-845.

Sheldon, I. M., S. B. Price, J. Cronin, R. O. Gilbert, and J. E. Gadsby. 2009b. Mechanisms of infertility associated with clinical and subclinical endometritis in high producing dairy cattle. Reprod. Domest. Anim. 44:1-9.

Sheldon, I. M., A. N. Rycroft, B. Dogan, M. Craven, J. J. Bromfield, A. Chandler, M. H. Roberts, S. B. Price, R. O. Gilbert, and K. W. Simpson. 2010. Specific strains of Escherichia coli are pathogenic for the endometrium of cattle and cause pelvic inflammatory disease in cattle and mice. PLoS ONE 5:e9192.

Silva, E., S. Leitão, T. Tenreiro, C. Pomba, T. Nunes, L. Lopes da Costa, and L. Mateus. 2009. Genomic and phenotypic characterization of Escherichia coli isolates recovered from the uterus of puerperal dairy cows. J. Dairy Sci. 92:6000-6010.

Stanisiewski, E., C. Daugherty, J. Hallberg, and M. Lucas. 2010. Evaluation of ceftiofur crystalline free acid sterile suspension (CCFASS) administered to dairy cows exhibiting risk factors for acute postpartum metritis. J. Dairy Sci. 93(E-Suppl. 1):408. (Abstr.)

Van Donkersgoed, J., M. Dussault, P. Knight, and L. Byers. 2008. Clinical efficacy of a single injection of ceftiofur crystalline free acid sterile injectable suspension versus three daily injections of ceftiofur sodium sterile powder for the treatment of footrot in feedlot cattle. Vet. Ther. 9:157-162.

Williams, E. J., D. P. Fischer, D. U. Pfeiffer, G. C. W. England, D. E. Noakes, H. Dobson, and I. M. Sheldon. 2005. Clinical evaluation of postpartum vaginal mucus reflects uterine bacterial infection and the immune response in cattle. Theriogenology 63:102-117.

Zerbe, H., C. Oßadnik, W. Leibold, and H. J. Schuberth. 2001. Influence of Escherichia coli and Arcanobacterium pyogenes isolated from bovine puerperal uteri on phenotypic and functional properties of neutrophils. Vet. Microbiol. 79:351-365. 